\title{
IMPLEMENTATION OF PI-RADS IN PROSTATE CANCER WITH 3 TESLA MRI- A PILOT STUDY
}

\author{
Adarsh K. M1, Muhammed Shahab M. K², Pavithra H³, Devadas Acharya4, Ravichandra G5, Vinayaka U. S6 \\ ${ }^{1}$ Assistant Professor, Department of Radiodiagnosis, Yenepoya Medical College, Mangalore, Karnataka. \\ 2Postgraduate Student, Department of Radiodiagnosis, Yenepoya Medical College, Mangalore, Karnataka. \\ 3 Postgraduate Student, Department of Community Medicine, Yenepoya Medical College, Mangalore, Karnataka. \\ 4 Professor and HOD, Department of Radiodiagnosis, Yenepoya Medical College, Mangalore, Karnataka. \\ 5 Professor, Department of Radiodiagnosis, Yenepoya Medical College, Mangalore, Karnataka. \\ ${ }^{6}$ Associate Professor, Department of Radiodiagnosis, Yenepoya Medical College, Mangalore, Karnataka.
}

\section{BACKGROUND}

\section{ABSTRACT}

For standardising of multiparametric magnetic resonance (MR) imaging of the prostate, the European Society of Urogenital Radiology published Prostate Imaging Reporting and Data System (PI-RADS) in 2012.1,2 Later it was validated and the PI-RADS sum score for summation of the single score for the three different pulse sequences (T2-weighted imaging, diffusion-weighted imaging [DWI] and dynamic contrast material-enhanced [DCE] was being used. MRI has an emerging role in facilitating the diagnosis of prostatic malignancy.

The purpose of the present study was to correlate the results of TRUS-guided targeted prostate biopsy with the PI-RADS scoring (Version 2) on MP-MRI in patients, wherein prostatic malignancy has been suspected.

\section{MATERIALS AND METHODS}

This was a descriptive study done at Yenepoya Medical College, Deralakatte, Mangalore over a period of 6 months after obtaining ethical clearance. 30 patients were included in the study.

Inclusion Criteria being-

- $\quad$ Patients with PSA > $4 \mathrm{ng} / \mathrm{dL}$.

- $\quad$ Patients with palpable lesion on digital rectal examination.

The data so obtained was tabulated in Excel Sheet and analysed for sensitivity, specificity and other statistical tests for individual parameters.

\section{RESULTS}

30 patients underwent MRI and TRUS-guided biopsy. Mean age of patients was 64 years, ranging from 52 - 79 years. All these patients had increased PSA levels. All these patients who underwent MP-MRI had a documented PI-RAD score. 4 of them had PIRAD I, 5 of them had PI-RAD III, 9 of them had PI-RAD IV and 12 of them had PI-RAD V. 21 patients with PI-RAD IV and PI-RAD V on imaging showed positive for malignancy on HPE showing significant association on Chi-square test with $\mathrm{x} 2=18.122$ and $\mathrm{p}=<0.001$ (statistically significant).

\section{CONCLUSION}

In our study, we found that a very good correlation with positivity of prostate cancer on HPE with higher PI-RADS (IV and V). PIRAD overall score was sensitivity (90\%) compared to its component alone (DWI- 69\%, T2- hypointensity- 68\%). This was similar to previous observation done by Junker et al. PI-RAD scoring is better done on 3 Tesla than 1.5 Tesla.

\section{KEYWORDS}

Multiparametric MRI (MP-MRI), Prostate Specific Antigen (PSA), Dynamic Contrast Enhancement (DCE), PI-RADS (Prostate Imaging Reporting and Data System).

HOW TO CITE THIS ARTICLE: Adarsh KM, Shahab MMK, Pavithra H, et al. Implementation of PI-RADS in prostate cancer with 3 tesla MRI- a pilot study. J. Evolution Med. Dent. Sci. 2018;7(14):1811-1814, DOI: 10.14260/jemds/2018/408

\section{BACKGROUND}

For standardising of multiparametric magnetic resonance (MR) imaging of the prostate, the European Society of Urogenital Radiology published Prostate Imaging Reporting and Data System (PI-RADS) in 2012.1,2 Later, it was validated and the PI-RADS sum score for summation of the single score for the three different pulse sequences (T2-weighted

'Financial or Other Competing Interest': None.

Submission 23-02-2018, Peer Review 18-03-2018,

Acceptance 26-03-2018, Published 02-04-2018.

Corresponding Author:

Muhammed Shahab M. K

Department of Radiodiagnosis,

Yenepoya Medical College, Mangalore, Karnataka.

E-mail:shahabmk@gmail.com

DOI: $10.14260 /$ jemds $/ 2018 / 408$

\section{(c) $($ ) $(5)$}

imaging, diffusion-weighted imaging [DWI] and dynamic contrast material-enhanced [DCE] was being used). After many years of practice, there was a modification of the same with single score system (on a scale of $1-5$ ), similar to this Breast Imaging Reporting and Data System was thought of. 3

Baur et al reported that assigning a PI-RADS score on the basis of DWI for PZ lesions and a PI-RADS score on the basis of T2-weighted imaging for TZ lesions was enough for patient workup and management, ${ }^{4}$ and this is why PI-RADS steering committee of the American College of Radiology developed PI-RADS version 2.0 .5

Clinical suspicion of prostate cancer is typically based on Digital Rectal Examination (DRE) and the finding of elevated prostate-specific antigen. ${ }^{6}$ Cancer may still be detected after initial negative biopsy with repeat TRUS biopsy, but the cancer detection rate falls with each repeat biopsy episode. ${ }^{7}$ 
MRI has an emerging role in facilitating the diagnosis of prostatic malignancy.8,9,10 Techniques typically involve MRI with morphological imaging, primarily high resolution T2weighted (T2W) imaging combined with one or more functional MRI techniques (Diffusion-Weighted Imaging [DWI], Dynamic Contrast-Enhanced imaging [DCE], Magnetic Resonance Spectroscopy [MRS]).8,9,10

The purpose of the present study was to correlate the results of TRUS-guided targeted prostate biopsy with the PIRADS scoring (version 2) on MP-MRI in patients, wherein prostatic malignancy has been suspected.

\section{MATERIALS AND METHODS}

\section{Patient Selection}

This was a descriptive study conducted at Yenepoya Medical College, Deralakatte, Mangalore, over a period of 6 months. Institutional Ethical Committee approval was obtained. Sample size was taken conveniently.

\section{Inclusion Criteria}

- $\quad$ Patient with PSA > $4 \mathrm{ng} / \mathrm{dL}$

- Patient with palpable lesion on digital rectal examination.

\section{Exclusion Criteria}

Patient with history of prostatic biopsy in past 6 weeks.

\section{Methodology}

After obtaining informed written consent, 30 patients who were suspected for prostatic cancer were subjected to multiparametric MRI followed by USG-guided 12 core biopsy. HPE result obtained was correlated with PI-RADS score.

\section{Multiparametric MRI Protocol}

All MRI imaging was done using phase array body coil on GE SIGNA Pioneer 3 Tesla. Parameter and sequence used are mentioned below.

\begin{tabular}{|c|c|c|c|c|}
\hline Sl. No. & Parameter & T2 & $\begin{array}{c}\text { DWI (b- } \\
\mathbf{8 0 0 )}\end{array}$ & Enhancement \\
\hline 1 & FOV & $28 \times 28 \mathrm{~cm}$ & $24 \times 12 \mathrm{~cm}$ & $28 \times 28 \mathrm{~cm}$ \\
\hline 2 & Matrix & $320 \times 256$ & $160 \times 80$ & $320 \times 256$ \\
\hline 3 & TR in msec & 5329 & 5040 & 590 \\
\hline 4 & $\begin{array}{c}\text { Section } \\
\text { thickness }\end{array}$ & $3 \mathrm{~mm}$ & $3 \mathrm{~mm}$ & $3 \mathrm{~mm}$ \\
\hline 5 & $\begin{array}{c}\text { Time for } \\
\text { acquisition }\end{array}$ & $\begin{array}{c}3 \mathrm{mins} 17 \\
\mathrm{sec}\end{array}$ & $\begin{array}{c}4 \mathrm{mins} 57 \\
\mathrm{sec}\end{array}$ & $2 \mathrm{mins} 43 \mathrm{sec}$ \\
\hline 6 & Spacing & $1 \mathrm{~mm}$ & $1 \mathrm{~mm}$ & $1 \mathrm{~mm}$ \\
\hline
\end{tabular}

\section{TRUS Guided 12 Core Biopsy}

Before the procedure, the patients were given broad spectrum antibiotics to protect them against infection. They were also given rectal enema to empty the rectal canal before the procedure to obtain clear images. Intrarectal instillation of $20 \mathrm{~mL}$ of local anaesthetic gel (Lidocaine $2 \%$ ) was used to alleviate pain and discomfort during the procedure.

A transrectal ultrasound probe (6-12 MHz range) with a combination of end-viewing and side-viewing transducer attached to GE Voluson E8 ultrasound machine was used. Local anaesthetic gel (lidocaine 2\%) was applied over a latex condom applied onto the probe. A full urinary bladder was ensured to help in better visualisation of the gland prior to the procedure. All patients were examined and biopsied in the left lateral decubitus position and it was well tolerated.

The prostate was imaged in both axial and sagittal planes with assessment of volume, echogenicity, surface, calcification and the presence of nodules.

Each nodule was assessed for size, location in the gland, morphology, echogenicity, margin and extent.

MR image of Prostate finalised were anaylsed by radiologist with 2-year experience and PI-RADS score were documented. HPE result was collected within 7 days to minimise error and was correlated with PI-RADS score.

FLOW CHART FOR THE DIAGNOSIS
Suspected case of prostatic cancer (PSA $>4 \mathrm{ng} / \mathrm{dl}$ ).
Underwent MP-MRI with the above mentioned parameters.
MRI images were reported by PIRADS score.
HPE results obtained were correlated with PIRADS score.

\section{Statistical Analysis}

The data obtained were analysed using Statistical Package for Social Sciences (SPSS) version 21. Histopathological findings were considered as the standard of reference and sensitivity, specificity, positive predictive value and negative predictive value were calculated for parameters DWI and T2 intensity. Comparative analysis of the quantitative data was done for categorical variables using chi-square test. All tests with pvalue $<0.05$ were considered as statistically significant.

\section{RESULTS}

\section{Evaluation of Diagnostic Test}

30 patients underwent MRI and TRUS-guided biopsy. Mean age of patients was 64 years ranging from 52 - 79 years. All these patients had increased PSA levels.

All these patients who underwent MP-MRI had a documented PI-RAD score.

4 of them had PI-RAD I, 5 of them had PI-RAD III, 9 of them had PI-RAD IV and 12 of them had PI-RAD V.

21 patients with PI-RAD IV and PI-RAD V on imaging showed positive for malignancy on HPE showing significant association on Chi-square test with $\mathrm{x} 2=18.122$ and $\mathrm{p}=<0.001$ (statistically significant).

\section{T2 Hypointensity}

Out of 30 patients who underwent MRI, 25 patients showed T2 hypointensity. 18 out of 25 patients showed positive on HPE with sensitivity of $68 \%$, specificity of $100 \%$ indicating that 18 patients with positive HPE had T2 hypointense lesion in the peripheral zone.

\section{DWI}

23 patients showed diffusion positivity, out of which 18 patients were positive on HPE which was statistically significant with ' $p$ ' value of 0.010 . 


\section{DCE Curve}

21 patients out of 30 had a dynamic enhancement curve of $B$ and $C(B=4, C=17)$. Out of 21 patients, 18 patients were positive on HPE.

\section{Overall PI-RADS Score}

Results were analysed using overall PI-RADS score. 90\% sensitivity with positive predictive value of $65.38 \%$ was documented and negative predictive value of $100 \%$ was documented.

\begin{tabular}{|c|c|c|c|c|c|}
\hline $\begin{array}{l}\text { Overall } \\
\text { PI- } \\
\text { RADS } \\
\text { Score }\end{array}$ & $\begin{array}{c}\text { Radiological } \\
\text { Given } \\
(n=30)\end{array}$ & \begin{tabular}{|c|} 
HPE \\
Malignant \\
Positive \\
$(n=18)$ \\
\end{tabular} & $\begin{array}{c}\text { Biopsy } \\
\text { Negative } \\
(n=12)\end{array}$ & $\begin{array}{c}\text { Chi- } \\
\text { Square } \\
\text { value }\end{array}$ & $\begin{array}{c}\mathbf{P} \\
\text { value }\end{array}$ \\
\hline 1 & 4 & - & 4 & \multirow{5}{*}{18.122} & \multirow{5}{*}{$<0.001$} \\
\hline 2 & - & - & - & & \\
\hline 3 & 5 & - & 5 & & \\
\hline 4 & 8 & 6 & 2 & & \\
\hline 5 & 13 & 12 & 1 & & \\
\hline \multicolumn{6}{|c|}{ DWI } \\
\hline 1 & 3 & - & 4 & \multirow{5}{*}{6.679} & \multirow{5}{*}{0.010} \\
\hline 2 & 1 & - & - & & \\
\hline 3 & 6 & - & 5 & & \\
\hline 4 & 7 & 6 & 2 & & \\
\hline 5 & 13 & 12 & 1 & & \\
\hline \multicolumn{6}{|c|}{ T2 } \\
\hline 1 & 2 & - & 1 & \multirow{5}{*}{7.846} & \multirow{5}{*}{0.005} \\
\hline 2 & 2 & - & 4 & & \\
\hline 3 & 5 & - & - & & \\
\hline 4 & 6 & 6 & 5 & & \\
\hline 5 & 15 & 12 & 2 & & \\
\hline \multicolumn{6}{|c|}{ DCE } \\
\hline A & 9 & 0 & 9 & \multirow{3}{*}{15.181} & \multirow{3}{*}{0.002} \\
\hline $\mathrm{B}$ & 4 & 3 & 1 & & \\
\hline $\mathrm{C}$ & 17 & 15 & 2 & & \\
\hline \multicolumn{6}{|c|}{$\begin{array}{l}\text { Table 1. Association between the Radiologically reported } \\
\text { Grading of CA Prostate and HPE Results }\end{array}$} \\
\hline
\end{tabular}

\begin{tabular}{|c|c|c|c|c|c|c|}
\hline 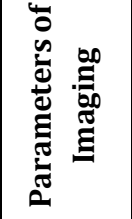 & 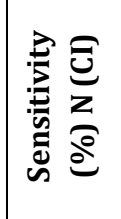 & : & 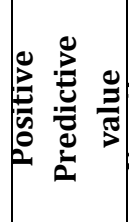 & 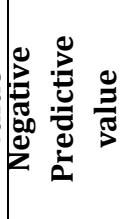 & 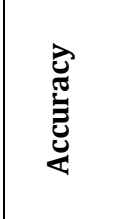 & 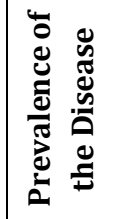 \\
\hline $\begin{array}{c}\text { PI-RADS } \\
\text { Score }\end{array}$ & $\begin{array}{c}100 \\
(80.49- \\
100.00)\end{array}$ & $\begin{array}{l}30.77 \\
(9.09- \\
61.43) \\
\end{array}$ & $\begin{array}{c}65.38 \\
(46.2- \\
80.6) \\
\end{array}$ & $\begin{array}{c}100 \\
(50.01- \\
99.99) \\
\end{array}$ & $\begin{array}{c}70 \\
(50.60- \\
85.27) \\
\end{array}$ & $\begin{array}{c}56.67 \\
(37.43- \\
74.54) \\
\end{array}$ \\
\hline DW & $\begin{array}{c}94.12 \\
(71.87- \\
99.01)\end{array}$ & $\begin{array}{l}46.15 \\
(30.11- \\
63.04)\end{array}$ & $\begin{array}{c}69.57 \\
(47.08- \\
86.79)\end{array}$ & $\begin{array}{c}85.71 \\
(42.13- \\
99.64)\end{array}$ & $\begin{array}{c}73.33 \\
(54.11 \\
87.72)\end{array}$ & $\begin{array}{c}76.67 \\
(57.72- \\
90.07)\end{array}$ \\
\hline $\begin{array}{c}\mathrm{T} 2 \\
\text { Intensity }\end{array}$ & 100 & $\begin{array}{c}38.46 \\
(26.09- \\
52.53)\end{array}$ & $-\left(\begin{array}{c}68 \\
(46.6- \\
85.05)\end{array}\right.$ & $\begin{array}{c}100 \\
(47.82- \\
100.00)\end{array}$ & $\begin{array}{c}73.33 \\
(54.11 \\
87.72)\end{array}$ & $\begin{array}{c}83.33 \\
(65.28- \\
94.36)\end{array}$ \\
\hline
\end{tabular}

\begin{tabular}{|c|c|c|c|}
\hline \multirow{2}{*}{$\begin{array}{c}\text { Parameter of } \\
\text { Imaging }\end{array}$} & Positive & Negative & \multirow{2}{*}{ Total } \\
\cline { 2 - 3 } & \multicolumn{4}{|c|}{ PI-RADS } \\
\hline Positive & 17 & 9 & 26 \\
\hline Negative & 0 & 4 & 4 \\
\hline Total & 17 & 13 & 30 \\
\hline \multicolumn{4}{|c|}{ DWI } \\
\hline Positive & 16 & 7 & 23 \\
\hline Negative & 1 & 6 & 7 \\
\hline Total & 17 & 13 & 30 \\
\hline \multicolumn{4}{|c}{ T2 intensity } \\
\hline Hypointense & 17 & 8 & 25 \\
\hline Hyperintense & 0 & 5 & 5 \\
\hline Total & 17 & 13 & 30 \\
\hline \multicolumn{4}{|c|}{ Table 3. Parameter of Imaging } \\
\hline
\end{tabular}

\section{DISCUSSION}

In our study, we found a very good correlation with positivity of prostate cancer on HPE with higher PI-RADS (IV and V). The study conducted by Kuru TH et al and five other studies observed positive correlation with prostate cancer detection and higher PI-RADS score. ${ }^{11,12,13,14}$

In our study, it was also found that patients with overall PI-RADS $<3$ had reduced incidence of prostate cancer when correlated with HPE. As a result, we can infer that multiparametric MRI with PI-RADS scoring reduces the need for biopsy in men with PI-RADS $<3$, while at the same time improving the overall rate of detection of intermediate/ highrisk prostate cancer.

Pokorny MR et al also observed that MP-MRI reduces need of biopsy in patients with lower overall PI-RADS score. 15

Overall, PI-RAD scoring in our study showed 90\% sensitivity compared to that of its individual components alone (DWI- 69\%, T2- hypointensity- 68\%), which was similar to previous observation done by Junker et al. ${ }^{16}$

We have detected clinically significant disease and other studies have shown that MRI reduces the need for biopsies and increases the detection of intermediate/ high-grade cancer. ${ }^{17}$

\section{CONCLUSION}

Multiparametric MRI of prostate has shown great promise for early detection of prostate cancer. PI-RADS version 2 is an improvement of the older version and it is a reliable tool for better communication between radiologists and clinicians in patients evaluated for prostate cancer. In addition to that, PIRADS version 2 scoring has significantly improved decision making with regard to need and guidance for biopsy.

\section{Limitation of Study}

- Sample volume of the study was small.

- PI-RADS scoring was done by single radiologist with multiple radiologists reviewing the same could have better scoring.

- Imaging protocol had only T2, DWI and DCE. The scoring would have been much better with MRS being done for all the cases. 


\section{REFERENCES}

[1] Muller BG, Shih JH, Sankineni S, et al. Prostate cancer: interobserver agreement and accuracy with the revised prostate imaging reporting and data system at multiparametric MR imaging. Radiology 2015;277(3):741-50.

[2] Barentsz JO, Richenberg J, Clements R, et al. ESUR prostate MR guidelines 2012. Eur Radiol 2012;22(4):746-57.

[3] Obenauer S, Hermann KP, Grabbe E. Applications and literature review of the BI-RADS classification. Eur Radiol 2005;15(5):1027-36.

[4] Baur AD, Maxeiner A, Franiel T, et al. Evaluation of the prostate imaging reporting and data system for the detection of prostate cancer by the results of targeted biopsy of the prostate. Invest Radiol 2014;49(6):41120.

[5] American College of Radiology. PI-RADS v2. Reston, VA: American College of Radiology. 2014.

[6] Yuasa T, Tsuchiya N, Kumazawa T, et al. Characterization of prostate cancer detected at repeat biopsy. BMC Urol 2008;8(1):14.

[7] Roehl KA, Antenor JA, Catalona WJ. Serial biopsy results in prostate cancer screening study. J Urol 2002;167(6):2435-9.

[8] Prando A, Kurhanewicz J, Borges AP, et al. Prostatic biopsy directed with endorectal MR spectroscopic imaging findings in patients with elevated prostate specific antigen levels and prior negative biopsy findings: early experience. Radiology 2005;236(3):903-10.

[9] Franiel T, Stephan C, Erbersdobler A, et al. Areas suspicious for prostate cancer: MR-guided biopsy in patients with at least one transrectal US-guided biopsy with a negative finding-multiparametric MR imaging for detection and biopsy planning. Radiology 2011;259(1):162-72.

[10] Sciarra A, Panebianco V, Ciccariello M, et al. Value of magnetic resonance spectroscopy imaging and dynamic contrast-enhanced imaging for detecting prostate cancer foci in men with prior negative biopsy. Clin Cancer Res 2010;16(6):1875-83.
[11] Kuru TH, Roethke MC, Rieker P, et al. Histology core-specific evaluation of the European Society of Urogenital Radiology (ESUR) standardised scoring system of multiparametric magnetic resonance imaging (mpMRI) of the prostate. BJU Int 2013;112(8):1080-7.

[12] Thompson JE, Moses D, Shnier R, et al. Multiparametric magnetic resonance imaging guided diagnostic biopsy detects significant prostate cancer and could reduce unnecessary biopsies and over detection: a prospective study. J Urol 2014;192(1):6774.

[13] Roethke MC, Kuru TH, Schultze S, et al. Evaluation of the ESUR PI-RADS scoring system for multiparametric MRI of the prostate with targeted MR/TRUS fusionguided biopsy at 3.0 Tesla. Eur Radiol 2014;24(2):34452.

[14] Reisæter LA, Fütterer JJ, Halvorsen OJ, et al. 1.5-T multiparametric MRI using PI-RADS: a region by region analysis to localize the index-tumor of prostate cancer in patients undergoing prostatectomy. Acta Radiol 2015;56(4):500-11.

[15] Pokorny MR, de Rooij M, Duncan E, et al. Prospective study of diagnostic accuracy comparing prostate cancer detection by transrectal ultrasound-guided biopsy versus magnetic resonance (MR) imaging with subsequent MR-guided biopsy in men without previous prostate biopsies. Eur Urol 2014;66(1):22-9.

[16] Junker D, Schafer G, Edlinger M, et al. Evaluation of the PI-RADS scoring system for classifying mpMRI findings in men with suspicion of prostate cancer. Bio Med Res Int 2013;2013(1):1-9.

[17] Jyoti R, Haxhimolla H, Jina NH. Correlation of high PIRADS score on three-tesla magnetic resonance with in-gantry magnetic resonance guided biopsy in patients with clinical risk of prostate cancer. Open Journal of Radiology 2016;6(01):62-7. 